\title{
Improving the quality of health care through contracting: a study of health authority practice
}

\author{
Jacqueline D Gray, Liam J Donaldson
}

\begin{abstract}
Objectives-To investigate approaches of district health authorities to quality in contracting.

Design-Descriptive survey.

Setting-All district health authorities in one health region of England in a National Health Service accounting year.

Material-129 quality specifications used in contracting for services in six specialties (eight general quality specifications and 121 service specific quality specifications)
\end{abstract}

Main measures-Evaluation of the use of quality specifications; their scope and content in relation to established criteria of healthcare quality.

Results-Most district health authorities developed quality specifications which would be applicable to their local hospital. When purchasing care outside their boundaries they adopted the quality specifications developed by other health authorities. The service specific quality specifications were more limited in scope than the general quality specifications. The quality of clinical care was referred to in $75 \%$ of general and $43 \%$ of service specific quality specifications. Both types of specification considered quality issues in superficial and broad terms only. Established features of quality improvement were rarely included. Prerequisites to ensure provider accountability and satisfactory delivery of service specifications were not routinely included in contracts.

Conclusion-Quality specifications within service contracts are commonly used by health authorities. This study shows that their use of this approach to quality improvement is inconsistent and unlikely to achieve desired quality goals. Continued reliance on the current approach is holding back a more fundamental debate on how to create effective management of quality improvement through the interaction between purchasers and providers of health care.

(Quality in Health Care 1996;5:201-205)

Keywords: quality of health care, purchasing, hospital, quality assurance

The United Kingdom National Health Service (NHS) is often viewed very positively internationally for providing and funding health care on a public basis in a way which promotes equity and access in health care. On the other hand, this same system has been criticised for failing to promote efficiency and quality. ${ }^{1}$

In 1990, in response to both these concerns and the international drive to contain costs of health care, ${ }^{2}$ the NHS underwent radical reforms, ${ }^{3}$ which changed responsibilities for provision and payment while maintaining the publicly provided model of health care. ${ }^{4}$ A split between purchasers and providers within an internal healthcare market was created. Within this reformed NHS, health authorities and general practice fundholders purchase health care on behalf of their resident or practice populations by placing contracts with hospitals and other providers of health services either in the private or public sector. The providers compete with each other by virtue of their ability to meet health authorities' contract specifications at competitive prices. ${ }^{5}$

A declared aim of the reforms was to raise standards and improve the quality of British health services. To this end, it was anticipated that purchasers would exploit the contracting system to specify their service quality requirements and that market forces would promote efficiency, quality, and patient responsiveness. ${ }^{6}$

In response to doubts about the purchasers' ability to exploit the contracting system to maximise quality of health care, ${ }^{78}$ we set out to study their approach in detail. Our objectives were to describe the application, scope, and content of quality specifications used in contracting for clinical services by all health authorities in a health region.

\section{Methods}

At the time of the study the NHS was divided geographically and administratively into 14 regional health authorities, each of which contained several district health authorities serving local populations. The district health authorities were responsible for purchasing health services to meet the assessed needs of their geographically defined resident population. The northern region, covering a population of about three million, was served by the Northern Regional Health Authority. During the study period (an NHS contracting year: 1 April 1993 to 31 March 1994) purchasing on behalf of health authorities in the northern region was undertaken by 11 purchasing organisations.

These purchasing organisations were asked to submit all quality specifications in the contracts for health care in six clinical specialties (selected to include acute, specialist, and 
continuing health services): general medicine, general surgery, ophthalmology, obstetrics, psychiatry, trauma, and orthopaedics. This request - to which all responded - resulted in eight sets of general quality specifications applicable to all contracts and 121 service specific quality documents.

With a standardised data collection form, one of us (JG) assessed each document for size and format; application of documents in contracting; categories of quality issue specified; nature of quality specifications (language and method used to specify quality requirements); and mechanisms for ensuring accountability and monitoring the delivery of the quality specifications.

\section{Results}

APPLICATION OF DOCUMENTS IN CONTRACTING The approach to contracting by all 11 purchasing organisations was virtually the same. Nine of the purchasing organisations used a general quality document with a wide range of quality specifications which were applicable to every contract placed and were not service specific. Because two purchasing organisations had adopted the same general quality document, there were only eight such documents for analysis. These purchasing organisations, and one other which did not use a general quality document (10 out of 11), also used quality clauses in service specific contract documents. The number of service contracts for each specialty varied between purchasing organisations and specialties. In some cases one service contract covered all services provided within a specialty, whereas in others there were separate service contracts to cover different elements of the service within a specialty. Furthermore, there were different service contracts for use with different providers of the same service. One purchasing organisation had not developed either general or service specific quality documents but had instead issued a general statement of commitment to quality. For these reasons there were 121 different service contract documents for analysis, from 10 purchasing organisations and six specialties.

Health authorities used the general quality documents and the service contracts which their purchasing organisation had developed when purchasing services from their local hospital or community unit. When purchasing care from providers of service outside their authority's boundaries, the health authorities adopted the quality specifications which had been developed by the relevant host purchasing organisation.

\section{DOCUMENT SIZE AND FORMAT}

The general quality documents were more extensive than the service specific contracts. The mean (range) length of the general quality documents was 19 (11-40) A4 pages compared with a mean (range) length of seven $(2-21)$ A4 pages for the service contracts.

The format of the general quality documents varied. Three were set out as a series of quality clauses, aims, or standards with the number of clauses ranging between 51 and 273. A further three general quality documents contained no specific quality clauses but consisted of a series of sections of narrative about quality issues. The remaining two general quality documents contained a very small section about quality but were chiefly concerned with general terms and conditions of service provision.

The service contracts were not attached to the general quality documents. Almost half $(46 \%)$ of the service contracts referred to the general quality documents and about one third $(32 \%)$ referred to other quality specifications which were neither attached nor referenced in a way which would enable them to be traced easily.

Reference to a strategic framework for purchasing quality was a feature of most of the general quality documents $(75 \%)$ but none of the service contracts. Two of the general quality documents set out specific details of the framework referring to a philosophy of quality and the need for quality assurance or improvement mechanisms. One of these documents also referred to the contracting process as an opportunity to promote quality and the need to respond to patient's views.

\section{CATEGORIES OF QUALITY ISSUE SPECIFIED}

The quality issues covered by both types of quality documents were not set out in any particular framework. Overall, the general quality documents were far more detailed than the service contracts. They mostly considered 11 categories of quality issue (table 1). All of them referred to the Patient's Charter, ${ }^{9}$ to customer and hotel services, to complaints procedures, and to safety and statutory regulations. By contrast, the service contracts considered only six categories of quality issue, none of which was common to every service contract (table 2). The proportion of service contracts which referred to the different categories of quality issue varied between specialties. For example, clinical care was referred to in $82 \%$ of the contracts for psychiatric services but was not referred to in any of the contracts for general surgical services.

\section{NATURE OF QUALITY SPECIFICATIONS}

The clarity and nature of the quality specifications set out in the various documents varied considerably. Often the statements were non-specific. This approach predominated in

Table 1 Categories of quality issue included most consistently in general quality documents of purchasing organisations

\begin{tabular}{ll}
\hline Category of quality issue & $\begin{array}{l}\text { General quality documents } \\
\text { referring to category (n(\%)) }\end{array}$ \\
\hline Patients' charter & $8(100)$ \\
Complaints procedures & $8(100)$ \\
Customer care and hotel & $8(100)$ \\
$\quad$ services & \\
Safety and statutory regulations & $8(100)$ \\
Medical or clinical audit & $7(88)$ \\
Service delivery & $7(88)$ \\
Human resources & $7(88)$ \\
Strategic quality framework & $6(75)$ \\
Clinical care & $6(75)$ \\
Health education and promotion & $5(63)$ \\
Care of the dying & $5(63)$ \\
Other & $4(50)$ \\
\hline
\end{tabular}


Table 2 Categories of quality issue included in contracts for services in six specialties

\begin{tabular}{|c|c|c|c|c|c|c|c|}
\hline \multirow[b]{2}{*}{ Specialty } & \multirow[b]{2}{*}{ Contracts (n) } & \multicolumn{6}{|c|}{ Service contracts considering category ( $n(\%)$ ) } \\
\hline & & Audit & Service delivery & Patients'charter & Human resources & Clinical care & Consumerism \\
\hline General medicine & 15 & $11(74)$ & $7(47)$ & $8(53)$ & $8(53)$ & $3(20)$ & $7(1)$ \\
\hline General surgery & 16 & $12(75)$ & $12(75)$ & $10(63)$ & $6(38)$ & 0 & $2(13)$ \\
\hline Trauma and orthopaedics & 17 & $12(71)$ & $12(71)$ & $11(65)$ & $7(41)$ & $4(35)$ & $3(18)$ \\
\hline Ophthalmology & 8 & $6(75)$ & $6(75)$ & $5(63)$ & $5(63)$ & $2(25)$ & $2(25)$ \\
\hline Obstetrics & 16 & 11 (69) & $7(44)$ & $9(56)$ & $6(38)$ & $9(56)$ & $6(38)$ \\
\hline Psychiatry & 34 & $25(74)$ & $27(79)$ & $28(82)$ & $21(62)$ & $28(82)$ & $12(35)$ \\
\hline Six specialties & 106 & 77 (73) & $71(67)$ & $71(67)$ & $53(50)$ & $46(43)$ & $32(30)$ \\
\hline
\end{tabular}

The Patient's Charter ${ }^{9}$ is a series of rights which United Kingdom patients can expect from their health services. These standards are monitored centrally as a measure of health service performance.

one of the general quality specifications which set out the following standards of nursing care:

"assistance will be available to patients; other professionals will be involved in the planning of care; the environment will be conducive to patient comfort; holistic care will be safely delivered."

Another common approach was to use an all encompassing statement which covered a specific issue but was nevertheless too broad to use - for example:

"the skill mix of staff involved in the delivery of contracts must meet an appropriate level of qualification and expertise, be adequate in numbers for the service being provided, and meet all statutory requirements" (stated in a general quality document) and: "adequate and appropriate staff will be available" (stated in a service specific quality document).

Much less often the approach was very specific clearly allowing providers to work to the specifications - for example, this extract from a service contract:

" All patients, or their relatives / carers will be introduced to the ward / department layout, facilities, routines, and safety procedures within two hours of admission".

\section{MECHANISMS FOR ENSURING ACCOUNTABILITY} AND MONITORING DELIVERY

The purchasers' usual approach to monitoring arrangements was to set out the intended arrangements in the general quality documents. These arrangements were given in broad terms and did not clarify details of how the different quality issues would be monitored. The categories of quality issue for which monitoring arrangements were most often described were the Patient's Charter," complaints procedures, and medical or clinical audit. Less often ( $38 \%$ of documents) monitoring arrangements were described for issues of service delivery. Only one general quality document referred to monitoring arrangements for human resources, safety and statutory regulations, and customer and hotel services. None of the general quality documents described monitoring arrangements for issues directly related to the quality of clinical care (table 3).

Explicit measures of performance such as performance standards and quality indicators were most commonly set out in the general quality documents. All purchasers referred to the Patient's Charter standards but explicit measures for other quality issues were included in $38 \%$ or less of the general quality documents. None of the purchasers specified explicit measures of performance for clinical care in their general quality documents (table 3). In the service contracts there were references to standards of professional practice. Table 4 shows the frequency with which these issues were considered. Standards of medical practice were described in $5 \%$ of service contracts. These standards focused on elements of the provision of clinical care rather than its content, appropriateness, or effectiveness - for example, "a paediatrician should examine every baby before discharge".

One purchaser referred to sanctions for failure to deliver quality specifications by outlining the negotiations which would follow if hospitals or other providers of service failed to deliver their general terms and conditions. However, no purchasers made any reference to sanctions in the event of providers failing to deliver any specific aspect of their quality contract specifications.

\section{Discussion}

Analysis of the extent to which health authorities have been considering quality improvement in contracts has been indirect ${ }^{10}$ or anecdotal. ${ }^{78}$ Our study represents the first attempt to systematically describe the approaches taken by local health authorities to improve the quality of care through the contracting process.

Table 3 Extent of use of mechanisms to ensure accountability for delivery of quality specifications in contracts

\begin{tabular}{|c|c|c|c|c|c|}
\hline \multirow[b]{2}{*}{ Mechanism } & \multicolumn{5}{|c|}{ General quality documents referring to mechanism (n (\%)) } \\
\hline & Patients'Charter & $\begin{array}{l}\text { Complaints procedures, and } \\
\text { safety and statutory regulations }\end{array}$ & $\begin{array}{l}\text { Clinical care and medical or } \\
\text { clinical audit }\end{array}$ & $\begin{array}{l}\text { Service delivery and } \\
\text { facilities }\end{array}$ & Human resources \\
\hline $\begin{array}{l}\text { Preagreed monitoring arrangements } \\
\text { Explicit measures of performance } \\
\text { Sanctions for non-delivery }\end{array}$ & $\begin{array}{l}7(88) \\
8(100) \\
0\end{array}$ & $\begin{array}{l}5(63) \\
3(38) \\
0\end{array}$ & $\begin{array}{l}4(50) \\
0 \\
0\end{array}$ & $\begin{array}{l}3(38) \\
3(38) \\
0\end{array}$ & $\begin{array}{l}1(13) \\
1(13) \\
0\end{array}$ \\
\hline
\end{tabular}


Table 4 Frequency with which standards of clinical care were defined in contracts for services in six specialties

\begin{tabular}{lclll}
\hline & & \multicolumn{2}{l}{ Service contracts } & featuring standards of practice ( $(\%))$ \\
\cline { 3 - 5 } Specialty & Contracts $(n)$ & Clinical practice & Medical practice & Nursing practice \\
\hline General medicine & 15 & 0 & 0 & 0 \\
$\begin{array}{l}\text { General surgery } \\
\text { Trauma and }\end{array}$ & 16 & 0 & 0 & 0 \\
$\quad \begin{array}{l}\text { orthopaedics } \\
\text { Ophthalmology }\end{array}$ & 17 & 0 & 0 & $1(6)$ \\
$\begin{array}{l}\text { Obstetrics } \\
\text { Psychiatry }\end{array}$ & 16 & 0 & 0 & 0 \\
Six specialties & 34 & $5(31)$ & $1(6)$ & $2(13)$ \\
& 106 & $8(24)$ & $4(12)$ & 0 \\
& & $13(12)$ & $5(5)$ & $3(3)$ \\
\hline
\end{tabular}

The material for study was representative of the documentation used by all health authorities in one English region contracting for quality in acute, chronic, community, and specialist services during the third year of the NHS reforms. Comparative performance data on aspects of quality (such as waiting lists and Patients' Charter standards) indicate that the region studied compared well with its counterparts in England. It is likely therefore that our findings could be generalised to the problems of achieving quality improvement through contracting in the NHS. The potential benefits of contracting are central to the philosophy underpinning the internal market. ${ }^{11}$ However, our study has shown fundamental flaws in the contracting process in relation to quality improvement.

We identified various weaknesses in the health authorities' approach to contracting for quality improvement. Firstly, there was little evidence to suggest that health authorities were systematically considering established features of quality improvement such as quality assurance based on objective measures. ${ }^{12}$ Nor was there any evidence of health authorities drawing on the established definitions and dimensions of quality in health care. ${ }^{1314}$ Also, different quality specifications were used with different providers of the same service and the health authorities only used the quality specifications which they had developed when purchasing services from their local hospitals. Consequently, the quality of services received by residents of a health authority, and the extent to which quality specifications reflected local needs, varied according to where they were treated. This situation was not conducive to building up a philosophy of quality which a health authority could transmit to its staff and the population it served.

Another problem was the use of many quality documents. The relation between these documents, which were often poorly referenced, was unclear. Thus a hospital or community health service seeking to deliver contracted quality specifications was put in a position of having to identify which documents were applicable, trace them, and then coordinate a range of unstructured material from often lengthy documents. Moreover, most health authorities set out their specifications in very broad or non-specific terms which were then open to different interpretations. Such an approach has several drawbacks. It might not promote delivery of the quality changes required and could encourage a provider of a service merely to pay lip service to a quality issue. Furthermore, the health authority specifying the requirement would be unable to measure, and hence monitor, whether the quality aspect of care that they required had been delivered.

The health authorities' focus on quality improvement through the contracting process was not directed towards the outcome of the healthcare intervention. The quality of clinical care was referred to in superficial terms and in only $43 \%$ of service contracts. Standards of medical care were defined in only $5 \%$ of service contracts.

Health authorities were not harnessing the power to improve quality which the contracting process afforded them. ${ }^{15}$ Their contracting documents did not include features to ensure the delivery of their quality specifications. Only a few of the quality specifications referred to preagreed monitoring arrangements or explicit measures of performance for specific quality issues other than the Patient's Charter. ${ }^{9}$ No health authority included sanctions for non-delivery of a specific issue.

At a practical level, it is essential to set our findings into context. Firstly, contracting is but one of many mechanisms through which quality improvement in United Kingdom health care can be, and is being, promoted. ${ }^{16}$ This remains so despite a further reorganisation of local health authorities in England. In practice, NHS managers seem to have greater faith in other approaches such as the current initiative to promote clinical effectiveness. ${ }^{17}$ Moreover, both purchasers and providers seem to place little value on contract documents as distinct from a more general collaborative approach to service development.

Since the introduction of the 1990 NHS reforms, health authorities have struggled to deliver numerous efficiency and quality targets in the face of unprecedented organisational change. Little formal training in either purchasing or quality management has been provided for those managers faced with delivering their new function. Further pressures to reduce management costs means that the opportunity to develop and maintain specialist skills in managing quality improvement through contracts is likely to be limited.

Increasingly general practice fundholding is assuming more of the responsibility for health care in the NHS. There is little evidence that these bodies have found a way of using contract specifications to achieve specific quality changes, apart from moving contracts from one hospital to another when there is dissatisfaction with the services provided.

Effective purchasing in relation to quality in health care is intrinsically difficult. ${ }^{18}$ There are particular problems in specifying measurable standards which can be readily monitored. Attempting to achieve key quality improvements through contracts is a method which is in common use in the NHS. Our study suggests that it is not an approach which is undertaken consistently, rigorously, or in a way which is likely to achieve desired quality goals. We think that continuing reliance on it is stultifying and is holding back a more fundamental debate on how to create effective management of quality 
improvement through the interaction between purchasers and providers of health care.

1 Roberts J. Navigating the seas of change. BMF 1991;302:34-7. 2 Ham C. Health care reform. BMF 1993;306:1223-4.

3 Secretary of State for Health. Working for patients. London: HMSO, 1989.

4 Nichol D. The evolving NHS market. The David McCullough memorial lecture; 1993. London: Chartered Institute of Public Finance, and Accountancy, 1993.

5 Abel-Smith B. The reform of the National Health Service. Quality Assurance in Health Care 1992;4:263-72.

6 Culyer AJ. The promise of the reformed NHS: an economist's angle. $B M \mathcal{F} 1991 ; 302: 1253-6$.

7 Gill M. Purchasing for quality: still in the starting blocks? Quality in Health Care 1993;2:179-82.

8 Sheldon TA, Borowitz $M$. Changing the measure of quality in the NHS: from purchasing activity to purchasing protocols. Quality in Health Care 1993;2:149-50.

9 Department of Health. The Patient's Charter. London: HMSO, 1991 .
10 Robinson R, Le Grand J. Evaluating the NHS reforms. London: King's Fund Institute, 1994.

11 Donaldson L. Building quality into contracting and purchasing. Quality in Health Care 1994;3:S37-40.

12 NHS Management Executive. The quality journey; a guide to total quality management in the NHS. Heywood: Health Publications Unit, 1993

13 Donabedian A. The definition of quality and approaches to its assessment. In: Donabedian A, ed. Explorations in quality assessment and monitoring 1980. Michigan: Health Administration Press, 1980.

14 Maxwell RJ. Quality assessment in health. BMf 1984; 288:1470-2.

15 Berwick DM, Enthoven A, Bunker JP. Quality management in the NHS: the doctor's role - 1. BMF 1992;304:235-8.

16 Donaldson LJ. Raising quality in the NHS: What progress? Quality in Health Care 1994;3:37-40.

17 National Health Service Executive. Improving clinical effectiveness. London: NHSE, 1993.

$18 \mathrm{McKee} \mathrm{M}$, Clarke A. Guidelines, enthusiasms, uncertainty, and the limits to purchasing. BMf 1995;310:101-4. 